J. Lake Sci.(湖泊科学) , 2008, 20(1): 1-12

http://www.jlakes.org. E-mail: jlakes@niglas.ac.cn

(C)2008 by Journal of Lake Sciences

\title{
天然有机质及其在地表环境中的重要性
}

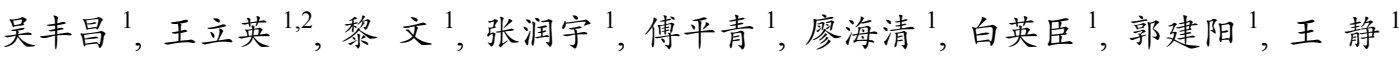 \\ (1: 中国科学院地球化学研究所环境地球化学国家重点实验室, 贵阳 550002) \\ (2: 中国科学院研究生院, 北京 100049)
}

摘 要: 天然有机质是地表各种环境介质中的重要化学组分, 分布广泛. 越来越多的研究已经表明: 它在地表生态系统的物 理、化学和生物过程中都起着十分重要的作用; 它与生态系统的各个重要环节密切相关, 是生态系统中能量与物质循环的重 要途径. 因此, 天然有机质不仅是生物地球化学、生态学和环境科学等研究领域的重要内容之一, 而且也是环境污染的评价、 预测和治理研究中的基础理论问题, 是目前环境质量、毒理学、环境立法和管理研究共同关注的科学问题. 本文主要以陆地 地表淡水湖泊与河流水环境为例，对天然有机质的来源、化学结构、循环特征，与养分循环的耦合关系，对有毒金属元素和有 机污染物迁移转化和毒性影响机理等几个方面的研究进展进行了简要的总结; 针对我国水体富营养化和环境污染等重要环境 问题, 阐述当前应该采取的研究思路和存在的主要科学内容, 并对现代有机环境与生物地球化学学科的研究趋势进行了展望. 关键词: 天然有机质; 生物地球化学; 环境污染; 环境地球化学

\section{Natural organic matter and its significance in terrestrial surface environment}

WU Fengchang ${ }^{1}$, WANG Liying ${ }^{1,2}$, LI Wen ${ }^{1}$, ZHANG Runyu ${ }^{1}$, FU Pingqing ${ }^{1}$, LIAO Haiqing ${ }^{1}$, BAI Yingchen ${ }^{1}$, GUO Jianyang ${ }^{1} \&$ WANG Jing ${ }^{1}$

(1: State Key Laboratory of Environmental Geochemistry, Institute of Geochemistry, CAS, Guiyang 550002, P.R.China)

(2: Graduate School of Chinese Academy of Sciences, Beijing 100049, P.R.China)

Abstracts: Natural organic matter is an important component in terrestrial surface environment. More and more researches indicated that it plays an important role in physical, chemical and biological processes of terrestrial ecosystem; it is the important cycling routes of matter and energy and relates with nearly all the important links of ecosystem. Natural organic matter is not only the important study field of biogeochemistry, ecology and environment sciences, but also a basic theoretical area in the assessment, prediction and control of environment pollution. Natural organic matter now becomes the focus of environment quality, toxicology, environment law and management. Using fresh lake and river as examples, this article briefly summarizes the study results of sources, chemical structure, cycling characteristics, coupling relations with nutrients cycling, and its effects on mobility and transformafion of toxic metals and organic pollutants, and expounds the possible right research directions and contents referring to water eutrophication and environment pollution. This article also makes a prospect about modern organic environment and biogeochemistry.

Keywords: Natural organic matter; biogeochemistry; environment pollution; environmental geochemistry

天然有机质来源于动植物体的分解残体，是结构和组分十分复杂，且物理上不均匀的有机混合物. 它在地表环境介质(大气、土壤、岩石、水体、沉积物)中普遍存在，具有重要的生态和环境意义. 作为全 球碳循环的重要组成部分, 它对全球变化有重要影响. 它也是生态系统中能量与物质循环的重要途径, 与生态系统的各个重要环节密切相关 ${ }^{[1]}$; 在流域与湖泊水生生态系统中, 天然有机质在各种物理、化学和 生物过程中均产生重要影响, 是各种养分(碳、氮、磷和硅)循环的关键环节, 是异养型微生物所需能源的 主要提供者, 是各种水体物理化学条件(溶解氧、酸碱度、颜色), 光合作用和 $\mathrm{CO}_{2}$ 水气交换等的重要影响

* 中国科学院重要方向项目(KZCX2-YW-102)、国家杰出青年基金项目(40525011)和国家自然科学基金重点项目(40632011) 联合资助. 2007-10-08 收稿; 2007-10-20 收修改稿. 吴丰昌, 男, 1966 年生, 研究员; E-mail:wufengchang@vip.skleg.cn. 
因素 ${ }^{[2-5]}$. 此外, 天然有机质还是环境污染物的重要络合剂或吸附剂, 对各种污染物的环境行为、毒性和 生物有效性有重要的影响; 在土壤和沉积物中, 有机质是疏水性有机污染物的主要宿体 ${ }^{[6-7]}$, 在水环境中, 有机结合态是许多有毒亲生物金属离子的主要赋存形式 ${ }^{[3,8-10]}$. 作为各种环境控制与治理技术(如厌氧/耗 氧等工艺、生态修复等)的选择、效率和工程评价等的重要影响因素, 有机质一直是饮用水水处理过程的 去除对象, 其特征直接关系到饮用水处理工艺的设计、效率和消毒副产品的形成等. 所以，天然有机质不 仅是生物地球化学和环境科学领域的研究热点, 而且是环境污染控制与治理技术实践研究中的理论基础, 是目前生态学、环境质量标准、毒理学、环境立法和政策管理研究共同关注的科学问题.

由于天然有机质的重要性及其化学组成、结构和来源的复杂性, 一直是国际生物地球化学领域的热 点和难点之一. 国际上较多的研究主要集中在海洋方面及其与全球变化有关的工作, 相对而言, 陆地地 表环境方面的工作开展得较少, 主要集中在其本身的生物地球化学循环及区域环境变化和污染物有关的 工作. 我国在该领域较早地开展了研究, 近年来取得了一些重要进展 ${ }^{[11-21]}$; 但相对而言, 这方面的研究 较为薄弱. 本文主要结合自己的研究成果, 从以下几个方面介绍最新进展、研究方向、存在的问题. 希望 更多的科学家共同关注这方面的工作, 共同建立陆地生态系统中有机生物地球化学过程、归宿及其与养 分循环的耦合关系，以及环境污染影响机理的基本框架，共同推进该领域的发展; 同时为毒性预测模型 的建立、环境质量评价和环境治理提供基础理论和技术支撑, 丰富和发展我国的环境与生物地球化学学 科.

\section{1 天然有机质的来源、化学组成与循环特征}

天然有机质作为全球碳循环的重要组成部分, 在所有水生生态系统如河流、湖泊、沼泽、地下水、 雨水、沉积物和孔隙水中广泛分布 ${ }^{[22-25]}$. 一般可分为颗粒态和溶解态，通常将能通过 $0.45 \mu \mathrm{m}$ 或 $0.75 \mu \mathrm{m}$ 玻璃纤维滤膜的有机质定义为溶解态, 其余的为颗粒态. 溶解有机质是天然水体中的重要化学组分.

\section{1 来源}

自然条件下水环境中的有机质可简单分为内源和外源, 内源与生物活动关系密切, 主要来源于水体 微生物或藻类分解, 而外源来源于土壤和动植物有机质的残体 ${ }^{[26]}$. 决定这两个来源对水体有机质相对贡 献大小的因素有多种, 包括水动力和寄宿时间、水体流域的自然地理特征和营养状态. 一般来说, 陆地水 体有机质主要是外源, 而海洋中以内源为主 ${ }^{[27]}$. 然而随着人类活动影响的加剧, 人为来源成为水环境中 有机质的一个重要来源. 不同水体环境中不同来源的比例是有差异的, 同时也是复杂多变的. 由于不同 来源有机质的环境行为与影响不同, 目前很多研究都集中于来源的辨识, 及其它们之间的转化过程. 来 源示踪的方法很多, 例如: 元素组成(C/N比值)、化学组分(氨基酸组成)、稳定碳/氮同位素, 苂光和紫外 光谱, 标志物有机化合物(木质素和糖类)方法等 ${ }^{[23,28-31]} . \mathrm{Wu}$ 等 ${ }^{[32]}$ 分析了云贵高原 6 个湖泊沉积物中 18 种氨 基酸组分在早期成岩过程的变化规律，发现含氮有机质优先降解，不同氨基酸有机质的来源也不同，色 氨酸主要与硅藻细胞壁选择性保存有关. $\mathrm{Wu}$ 等 ${ }^{[33]}$ 发现日本琵琶湖水体不同分子量溶解有机质的苂光和 紫外、氨基酸组分和分子量分布之间存在明显的内在关系，推测大分子有机质可能部分来源于生物成因， 水体溶解有机质存在从分子量大到小的降解路径，表明水体中不同来源有机质之间的复杂转化关系. 对贵州红枫和百花两湖溶解有机质的时空分布规律进行研究, 发现其来源存在明显的季节性变化特征 ${ }^{[29]}$; 发现利用不同来源有机质荧光和溶解有机碳比例的差异, 可以初步分析陆源输人和初级生产力对有机质 的相对贡献 ${ }^{[23,29]}$. Fu等 ${ }^{[25]}$ 以贵阳南明河为例, 研究了城市水体有机质的来源, 变化规律及其与其它化学 组分的关系. 对湖泊而言, 表层沉积物孔隙水中有机质可以是上覆水体的几倍到几十倍, 因此也是上覆 水体的一个潜在来源 ${ }^{[23]}$.

\section{2 组成与化学结构}

天然水体中总有机碳的浓度范围为 1-40 mg/L $\mathrm{L}^{[34]}$; 通常, 在海水中为 $0.5 \mathrm{mg} / \mathrm{L}$, 江河中可高达 $7 \mathrm{mg} / \mathrm{L}$, 湿地和沼泽中可高达 $25 \mathrm{mg} / \mathrm{L}$. 溶解有机氮的浓度最高可达到 $100 \mu \mathrm{M}^{[35]}$, 其中氨基酸和尿素可占总量的 $25 \%$ 和 $10 \%$, 其余为氨基糖、核酸、叶绿素及其它相关色素、胺类和维生素 ${ }^{[36]}$. 腐殖质(腐殖酸和富里酸)是溶 解有机质的主要组分; 以碳计，它可占总有机质的 $40 \%-80 \%{ }^{[37]}$; 腐殖质碳约占海洋有机碳的 $20 \%$, 河流 
的 $60 \%$, 湿地的 $70 \%$. 以外, 还含有一些亲水性有机酸、羧酸、氨基酸、碳水化合物等 ${ }^{[34]}$; 碳水化合物可 占溶解有机质的 $1 \%-30 \%$, 氨基酸可占溶解有机质的 $1 \%-3 \%{ }^{[32,34,38]}$. 腐殖质比较难降解, 而碳水化合 物、蛋白质、氨基酸和有机酸等则比较溶解降解 ${ }^{[31]}$. 目前已确认的化学组分只占总有机质的不到 $25 \%$, 大 部分是未知的, 研究程度相对较低 ${ }^{[34]}$.

对于元素组分，溶解有机质含 $\mathrm{C} 、 \mathrm{H} 、 \mathrm{~N} 、 \mathrm{O} 、 \mathrm{~S}$ 等元素，其中碳和氮是腐殖质的主要组成元素之一，碳、 氮元素可分布在环上和链上. 氮多以氨基形式存在 ${ }^{[39]}$, 杂环氮化合物含量很少. 在易降解的部分溶解有 机质中，氮元素的含量更高. 碳是有机质的骨架元素，其质量通常占有机质的一半以上. 对于有机质特 征，它们的分子量分布、荧光特征、化学组分等物理化学结构之间也存在内在关系 ${ }^{[33,39-42]}$.

天然有机质结构认识主要从腐殖质的化学结构开始, 最早可以追溯到 18 世纪. 总的来说, 尽管有机 质结构目前还不完全清楚，但是取得了重要进展，特别是近年来，人们运用多种现代技术，如: ${ }^{13} \mathrm{C} /{ }^{15} \mathrm{~N} /{ }^{31} \mathrm{P}-\mathrm{NMR}$ 、红外光谱、离子亲合色谱、高效液相色谱、高分辨质谱、气体质谱仪和质差热分析等 [32,40-47], 对有机质的化学结构有了更多的了解. 其中, 目前高分辨质谱和核磁共振技术是有机质结构特 征较好的研究手段.

现代仪器分析方法可以不破坏有机质原有结构的前提下提供元素组成和官能团信息. 如用体积排阻 色谱 ${ }^{[4,41,48]}$ 、膜透析、超滤 ${ }^{[49]}$ 等技术对有机质进行分子量分级, 以此表征有机质中不同组分的化学性质差 异 ${ }^{[47]}$. 从 ${ }^{13} \mathrm{C}-\mathrm{NMR}$ 谱图中可以认识到腐殖酸结构中含有大量的长链烷烃，一定量的芳香基、羧基和碳水 化合物; 富里酸则含有大量羧基、碳水化合物及多糖，芳香基和烷烃为其主要结构特征.

目前一般认为，水环境中腐殖质具有苯环羧基和酚基官能团构成的聚苯环和某些基于氮和硫原子的 基团或键，所含官能团主要有羧基、醇羟基、酚羟基、醌型羰基和酮型羰基等，其中羧基约占总酸性基 团的 $60 \%-90 \%$, 水体中腐殖质的大分子结构也会随着其来源以及溶液水化学的改变而改变 ${ }^{[50]}$.

\section{3 迁移转化与输出过程}

不同来源的有机质在地表环境中可以发生分解和转化等作用, 这些过程受水体特有的物理化学及生 物过程控制. 物理化学过程包括吸附、解吸、溶解、凝聚和缩合等, 以及氧化还原作用与光化学反应, 生 物过程则主要与生物活动有关.

1.3.1 物理化学过程 有机质本身为带弱负电荷的聚合体, 因此水体中一些条件的变化将会影响到有机质 的物理化学形态. 例如胶体部分由于电中和将会发生絮凝，而溶解态部分可能吸附到絮状物或者金属水 化合物上并一起沉淀. Stumm 和 Morgan ${ }^{[51]}$ 认为湖泊水体中的一些溶质(例如钙、锰、铁和铝)对于有机质 转化的影响可能与生物作用和光分解作用的影响相当. 碳酸盐地区的高钻镁浓度是引起喀斯特地区地表 水体中溶解有机质含量较低的主要原因之一. 在许多半干旱地区，与人湖河流相比湖泊水体中的盐度较 大，有机质发生聚合和沉淀作用的可能性很大.

有机质还可发生一系列分子内和分子间的缩合反应. 沉积物相对于水体是一种更利于有机质发生分 子间缩合反应的介质 ${ }^{[52]}$. 沉积物中有机质在矿化过程中可形成易降解的氨基酸组分等中间产物，而聚合 和腐殖化等反应的最终结果可能形成较难降解的成分 ${ }^{[53]}$. 欧洲康士坦茨湖的沉积物深度剖面表明: 沉积 物的腐殖化包括降解与聚合这两个同时进行的过程 ${ }^{[54]}$. 洱海湖泊沉积物中有机质在早期成岩阶段符合快 和慢的两阶段分解模式 ${ }^{[23]}$.

光化学反应可使有机质降解成为小分子的有机物与简单产物，包括: $\mathrm{H}_{2} \mathrm{O}_{2} 、 \mathrm{CO} 、 \mathrm{CO}_{2}$ 、乙醛、酮类、 氨基酸、氨 ${ }^{[55]}$. 从天然水体中分离出的腐里酸和胶体部分经光化学反应释放自由氨基酸, 经光照射后水 中有 20 种肽的浓度上升. 水环境中有机质光降解的速率受到有机碳浓度、光的吸收及水的苂光特征、照 射波长、 $\mathrm{pH}$ 和铁含量等因素的影响 ${ }^{[66-57]}$. 有机质的光降解可以导致其与金属离子络合能力的降低 ${ }^{[43,57-58]}$, 还可能提高有机质的抗生物降解能力和生物可利用性. 一般认为: 水体中抗生物降解的大分子部分(包 括腐殖物质)被阳光照射后会释放含氮丰富的化合物，包括氨(尤其是紫外光的照射). 对于整个水体来 说，导致有机质矿化的主要是生物过程. 例如：亚马逊河表层水中有机质的光化学消耗量是细菌消耗量 的 7 倍, 但整个水柱中微生物引起的矿化是有机质消耗的主要过程, 并且整个水体中只有 $15 \%$ 的有机质具光活 性 ${ }^{[59]}$. 
1.3.2 生物过程 生物是水体有机质各种反应最具活力的参与者, 包括浮游植物和浮游动物, 大中型的水 生植物和水生动物以及其他微生物. 生物活动尤其是浮游植物的光合作用能生产有机质, 同时也参与有 机质在水体中的迁移转化过程. 浮游植物释放的有机质可在 $24 \mathrm{~h}$ 内被细菌利用 ${ }^{[52]}$. 而表层沉积物中各种 生物扰动作用对于沉积物与上覆水体之间有机碳和有机氮的交换将会产生很大的影响, 可能使得沉积物 向上覆水体的扩散通量增大 ${ }^{[53,60]}$.

在以微生物活动为基础的水生生态系统食物网中, 溶解有机质是重要的能量和营养来源, 对浮游植 物和细菌的生物活动产生影响. 例如: 有 $12 \%-72 \%$ 的溶解有机氮能迅速被生物利用 ${ }^{[61]}$. 当溶解有机氮和 铵分别作为生态群落的氮源时, 浮游植物群落的组成将有所不同 ${ }^{[62]}$. 而一些与生物活动密切相关的有机 质成分则对生态健康具有潜在的指示意义, 例如碳水化合物 ${ }^{[63]}$. 糖䤊酸是一种酸性多糖, 由藻类、细菌在 低营养、高金属离子浓度的压力情况下分泌，可成为水环境中重金属的解毒物质 ${ }^{[64]}$.

\section{4 存在的主要科学问题和研究方向}

由于有机质研究的难度和复杂性, 尽管对天然有机质的来源、化学组成与循环特征已经开展了很多 研究, 但其独特的生物地球化学特征包括来源 (光合作用、各种微生物活动、浮游生物和动植物)相对贡 献, 保存(沉降、凝聚、聚合、吸附与复合、腐殖化作用)和分解与转化(有氧降解、缺氧降解、矿化、及 缩合作用)机理等, 及其在生态系统中的功能的研究比较零散, 不够系统和深人. 需要开展深人研究的方 向包括: (1)各种典型地区流域内各环境介质中天然有机质(颗粒态和溶解态)的含量水平、时间和空间分 布规律, 以及化学组分与主要化学官能团特征; 有机质从流域到河流, 到水体及沉积物体系中各种过程 (岩石风化成土过程、土壤风化淋溶过程、土壤/植物界面、湖泊沉降作用、氧化还原作用和早期成岩作 用)的源汇与分解转化规律、通量与速率等. (2)各种地球化学因素如: 酸度、太阳紫外辐射、生命活动(微 生物)等对有机质化学结构和分解转化过程的影响机理的室内和室外模拟研究, 特别是微生物参与下有 机质的生物地球化学行为是该领域研究的薄弱环节.

地表环境各个界面是有机质发生剧烈分解转化的活跃场所, 发生着多种重要的物理、化学和生物作 用, 直接影响着地表环境的物质循环, 及污染物的环境行为. 所以, 有必要对有机质在各种重要界面的 来源、含量、空间分布、分解转化的速率、通量和主要物理、化学和生物影响因素进行深人研究. 主要 研究内容包括: (1)岩石/土壤和土壤/植被界面与典型小流域水文地球化学循环中有机质转化特征. (2)岩 石/土壤界面, 在生物作用和化学风化过程中有机质的释放规律以及控制释放的微界面, 如水/粒界面吸 附解吸过程、水/矿物界面化学反应过程等. (3)土壤/植被界面, 重点研究植物根区附近有机质的形态转化 与分解转换的规律. (4)典型小流域水文地球化学循环, 可以通过大气降水、地表水、土壤水和地下水的 化学和同位素组成的研究, 揭示水体有机质化学组成、来源及循环规律.

考虑到有机质含量范围与化学结构的复杂性, 往往需要将有机质进行分离富集后再分别进行研究. 对于固体环境介质(土壤和沉积物等)通过化学分析方法将有机质分离成胡敏素、腐殖质和其它难降解等 各种有机质组分; 水样(大气降水、地下水、地表水和孔隙水等)则可以通过各种 XAD 和离子交换系列树 脂将溶解有机质分成多种性质不同的疏水与亲水性组分, 然后运用综合手段对这些不同有机组分进 行深人详细的化学结构解析. 揭示有机质的来源、化学组成与循环特征等方面的差异特征是未来研究 的重点

\section{2 有机质与养分循环之间的耦合关系}

天然有机质与养分(氮和磷)都是水生生物的 “食物”, 是完整生态系统中能量与物质循环的重要组成 部分, 与生态系统的各个重要环节密切相关. 近期研究显示: 溶解有机质与水体中的营养盐负荷和食物 网的结构决定着水生生态系统的属性和动态 ${ }^{[65]}$. 有机质和养分与初级生产力和微生物活动等密切相关, 并且一起参与生态系统中各种重要的物理、化学和生物过程, 伴随着它们组分含量和化学结构的改变; 它们之间的耦合关系主要是指这些过程中有机质与无机养分的降解(利用)、转化发生的复杂的相互作用 等. 养分 $(\mathrm{N}, \mathrm{P}, \mathrm{Si}, \mathrm{C})$ 本身就是有机质的主要化学组成. 例如: 有机质降解过程中大量耗氧, 同时释放出 C、N、P、S 等有机和无机营养盐, 进而影响各种养分的吸附/解析、相互转化及生物利用等过程. 


\section{1 有机质与氮的耦合关系}

氮是湖泊水生生态系统中重要的营养元素之一, 与水体初级生产力有着密切的关系. 水体中的氮循 环及其环境生态效应研究是长期以来研究的热点领域 ${ }^{[6-67]}$. 氮以有机氮和无机氮两种形态存在地表环境 中, 目前这一领域的缺陷主要是有机氮, 及其与无机氮转化关系研究的不足. 因此, 对涉及到有机氮的 反应和过程缺乏了解, 对有机质与氮耦合关系, 及氮循环的认识还不够完善.

有机氮可分为颗粒态和溶解态两种. 颗粒态有机氮主要包括生物碎屑和活的生物体, 有机氮主要包 括蛋白质、肽、氨基酸、氨基糖、核酸、叶绿素及其他相关色素、腐殖质等 ${ }^{[32]}$. 最近研究表明, 有机氮 库是氮循环中一个重要的储存库和转换环节. 有机氮直接参与固氮、同化、氨基化等氮循环过程, 它们 与无机氮不断的相互转化. 如: 颗粒态有机氮的沉降是水体中的有机氮进人到沉积物的主要方式; 溶解 有机质在输送过程中矿化成为氮的内源, 与此相关的化学计量学对水生态有重要影响 ${ }^{68]}$. 沉积物中的氮 也主要以有机氮的形式存在, 珠江口沉积物中有机氮占总氮的 $79 \%$; 溶解有机氮可与其他无机氮形态一起 参与到水体中最活跃的生物过程, 在多数天然水体中溶解有机氮是溶解性总氮的主要组成部分, 所占百分 比为 $60 \%-69 \%{ }^{[66]}$. 有 $12 \%-72 \%$ 的溶解有机氮能迅速被生物利用 ${ }^{[6]]}$. 而浮游植物吸收的无机氮有 $25 \%-41 \%$ 是以溶解有机氮的形式释放 ${ }^{[69]}$. 这些过程的反应速率和对生态系统的影响程度与地表环境有着密切的联 系. 湖泊水体和沉积物中碳氮循环研究的困难在于: 环境中各种物理化学条件和生物参数在时间和空间 上是不断变化的, 同时它们各个单独过程是互相关联的, 不同的影响因素产生的效果可能是互相叠加的. 因此，只有对系统进行原位动态的研究才可能获得有用的信息.

地表环境各个界面是有机质降解和碳氮耦合最为强烈的场所, 发生着剧烈的交换、降解、转化和埋 藏过程. 目前稳定同位素被认为是示踪环境中发生的生物、物理化学过程的有效手段; 各种形态含量结 合一些现代同位素和结构分析如 ${ }^{15} \mathrm{~N}$ 核磁共振可望深人揭示碳与氮之间的耦合机制.

与无机氮相比, 水体中有机氮的研究目前还开展得较少. 尤其是对于溶解有机氮的研究, 这是由于 水体中的溶解有机氮是成分复杂的混合物且浓度很低, 准确测定其浓度存在困难, 目前还只能间接测定. 几年前国际上还在对其测定方法进行讨论 ${ }^{[30,70]}$. 目前国际上对于水体中溶解有机氮浓度的时间和空间分 布、溶解有机氮的化学组成和结构、溶解有机氮的来源和转化及其生态环境效应等方面的认识还不是很 清楚 ${ }^{[66]}$.

\section{2 有机质与磷的耦合关系}

地表中磷可分为无机磷和有机磷. 无机磷一般和铁、铝、钙等化合物或粘土矿物结合在一起, 受环 境条件变化影响较大; 有机磷则为各种含磷有机化合物或与有机体鳌合的磷, 其组分相对复杂 ${ }^{[71]}$. 由于 研究手段的限制, 目前有机磷的组成结构、化学形态和性质仍不很清楚; 已有的方法仅限于分析与有机 物结合的总磷; 有机磷通常只作为无机磷萃取后的残渣或难溶部分 ${ }^{[72]}$, 运用总磷和无机磷差减计算而得. 最近二十多年, 有机磷及其与有机质、各种磷或本身的相互转化关系才逐渐引起人们的关注. 现代分析 方法的发展, 如核磁共振技术 ${ }^{[73]}$ 和酶分析技术 ${ }^{[74]}$, 为进一步研究提供了宽广的空间 ${ }^{[75-78]}$.

氮和磷均是天然有机质(包括不同来源腐殖质)的主要组成部分之一 ${ }^{[79]}$. 由于有机质对金属 $\mathrm{Al}$ 和 $\mathrm{Fe}$ 等 很强的亲和力, 并可以形成有机质一金属一磷络合物 ${ }^{[0]}$, 进而在这些物质生物地球化学循环中相互影响. 目前对地表环境中有机质和磷生物地球化学均开展了大量的研究工作 ${ }^{[81]}$, 但它们之间的相互关系却鲜有 报道 ${ }^{[79,82]}$.

微生物在地表环境营养物质的生物地球化学循环过程中具有十分重要的作用; 作为水生生态系统 中的一大类群, 微生物既是有机质的分解者, 又是重要的生产者. 有机质主要通过微生物转化成为生物 可直接利用的营养物质, 这些营养物质释放到水体中供浮游生物利用, 这一过程构成物质的循环 ${ }^{[83]}$. 因 此, 有机质的降解和各种转化的速率很大程度上取决于细菌的丰度. 因此, 如何揭示微生物在有机质与 养分耦合循环之间的作用机理将成为以后研究的重点.

\section{3 未来主要研究方向}

有机质、水分和营养组分循环密切相关, 它们直接影响着生态系统的物质与能量的转换. 目前从流 域土壤、河流到湖泊水体、沉积物等体系仍缺乏系统研究, 重要界面的某些关键机理与过程认识不足. 因 
此, 需要选择典型重点区域, 深人开展有机质与养分在流域岩石土壤风化淋溶/水土流失、各种生物作用、 现代沉积作用与早期成岩作用等过程中的耦合关系, 及主要地球化学影响因素等的研究. 主要研究内容 包括: (1)各环境介质含氮和磷的主要有机组分, 同位素(包括单体同位素)及化学结构特征. (2)有机质与养 分(氮、磷、硅和碳)在土壤、河流和湖泊水体与沉积物中的组分含量、形态与同位素的时间与空间分布 规律, 及主要影响因素. (3)研究我国不同土壤类型、气候条件、土地利用方式和管理方式下, 天然有机质 与营养组分的产生与保存、总体水平和形态含量的宏观分布特征; 揭示不同物理、生物化学性质、气候 和各种水热条件对土壤有机质降解速率、不同类型碳组成与营养组分转化的影响. (4)有机质和营养组分 在水/土、植被/土壤、气/水、沉积物/水等各界面的分解转化机理, 耦合关系及主要影响因素; 界面过程 应该包括通量、速率与分解转化规律, 影响因素应该包括物理作用、生物(微生物)活动, 氧化还原条件及 早期成岩作用等.

在某些特殊地区如西南喀斯特地区, 这里水土流失严重, 有机质和养分有独特的产生、分解和保存 方式. 因此, 有机质与养分循环耦合机制是认识这些脆弱生态系统退化过程中的恢复和优化调控的科学 基础. 因此, 可以选择典型喀斯特小流域, 根据石漠化过程的不同阶段或生态演替阶段, 分别研究有机 质与营养组分在生态系统退化不同阶段的循环特征. 主要内容可包括: (1)生态系统退化过程中物质与能 量循环主要途径分析; (2)在生态系统退化不同程度或阶段, 有机质与养分(营养组分, 生物大分子和小分 子化合物)在岩石风化淋溶与水土侵蚀过程中的含量、通量、组分和同位素等的响应特征; (3)在生态系统 退化不同程度或阶段, 有机质与养分(营养组分, 生物大分子和小分子化合物)在河流与湖泊水环境中的 含量、通量、组分和同位素等的响应特征; (4)控制或影响小流域有机生物地球循环特征的主要地质因素. 具体研究方法可以结合基岩性质、土壤类型、水文条件等因素，在详细的气象、水文、地质、化学、生 物连续观测基础上, 利用元素、同位素 $\left(\right.$ 如 $\delta^{13} \mathrm{C} 、 \delta \mathrm{D} 、 \delta^{18} \mathrm{O} 、 \delta^{15} \mathrm{~N}$ )示踪和化学计量学理论和方法、核磁共 振 $\left({ }^{31} \mathrm{P} /{ }^{13} \mathrm{C} \mathrm{NMR}\right)$ 、质谱、红外光谱、紫外、荧光光谱和元素等分析, 开展营养物质的有机质, 如生物体、 生物大分子(核酸)、生物小分子(烷烃、类脂化合物、氨基酸等)、氮、磷、碳和硅等化学形态等分析，阐 述耦合过程的组成组分、分解转化、通量速率及循环特征.

\section{3 天然有机质对环境污染物的影响}

天然有机质是地表环境有毒污染物的重要化学络合剂和吸附剂, 直接影响它们的迁移转化、毒性、 生物地球化学循环及归宿 ${ }^{[3-4,18,48,84-86]}$. 因此, 有机质与污染物相互作用是环境污染过程、修复治理及其与 人体健康关系研究的关键科学问题. 长期以来, 国内外学者对化学污染物在地表环境中的迁移转化行为 和毒性进行了大量研究 ${ }^{[87-91]}$. 最早人们往往比较关注污染物的总含量, 后来逐渐认识到污染物化学形态 的重要性, 特别是金属元素的毒性和生物有效性主要与化学形态有关 ${ }^{[92]}$. 而具体到水体中由于溶解有机 质具有很强的反应活性和迁移活性 ${ }^{[3]}$, 直接影响水体的酸碱度和溶解氧的循环, 对水体中的微量金属离 子和有机污染物的形态毒性、迁移转化和生物有效性有重要影响 ${ }^{[93]}$.

最新研究表明: 生物和有机质在污染物生物地球化学过程中起着十分重要的作用 ${ }^{[94]}$. 溶解有机质能 与金属离子形成有机金属络合物, 导致金属离子生物地球化学行为的改变, 影响其溶解性、生物有效性、 与微粒之间的相互作用并改变它们的毒性, 有机质对水环境中的许多微量金属如录、铜、铅、钴和铁等 的生物地球化学循环过程起着十分重要的作用 ${ }^{[3-4,48,84-85]}$. 对生物体而言, 游离态金属(如铜和锌)比有机 络合态更具毒性，不过有机一金属配位体可能代表着一种潜在的毒源，因为金属离子有机态和无机态之 间的平衡随时可能被水体物理化学性质的改变而打破，而当有机质吸附到胶体或颗粒物上后将会使它们 的稳定性发生改变. 有机质与无机(如金属离子)或有机(如杀虫剂)的污染物络合后能提高它们溶于水的 能力和在水中的迁移能力, 但与有机质的络合会降低这些污染物的生物有效性 ${ }^{[37]}$. 因此, 金属与有机质 的相互作用机理也是近年来金属和有机生物地球化学研究领域关注的焦点. 例如: 控制金属铜离子的两 种主要有机配位体的来源和主要地球化学特征(化学结构, 分子量, 荧光特征, 氨基酸组分, 化学官能团 及其它化学结构)与行为均存在明显差异 ${ }^{[3-4,48,95]}$. 溶解有机质还与金属离子(如录、铅、镉、锌等)存在明 显的结合作用 ${ }^{[24-25,43,96]}$, 有机质不同组分明显控制各种金属在水环境中的分布特征 ${ }^{[97]}$. 目前国际上研究 
主要在有机配位体的浓度及其与某些金属的络合稳定常数等方面积累了大量数据，而对影响金属毒性的 有机质本身的地球化学特征及其在水环境中的命运和归宿等的研究仍然较少; 对与有机污染物结合的有 机质结构特征和转化规律研究还需深人. 通过不同来源有机质与不同价态有毒污染物结合行为(结合常数 和容量)和结合机制的研究, 及污染物在沉积物、土壤颗粒物中的吸附/解吸动力学过程与影响因素的研究, 并结合天然有机质本身在地表环境中的行为, 可望全面阐述有毒污染物在地表环境中的生物地球化学行 为, 为环境污染毒性评价和预测等提供基础数据, 丰富和发展无机和有机, 有机与有机相互作用理论.

土壤，微粒和沉积物中有机质(主要是胡敏素)的吸附/解吸作用基本控制了有机污染物的生物地球化 学循环和归宿 ${ }^{[8]}$. 例如: 吸附作用是控制土壤和沉积物有机污染物的行为和重要过程, 在土壤和沉积物系 统中 $(>0.1 \%$ 有机碳 $)$, 天然有机物是疏水性有机污染物的主要吸附剂. 例如: 腐殖质结合占土壤总多氯联 苯和多环芳烃的 $70 \%-80 \%{ }^{[6-7]}$. 最近研究发现: 溶解有机质对一些药品和个人护理品如卡马西平有强烈 的相互作用, 模型预测在一般地表水体中, 溶解有机质主要(33\%-86\%)控制着它们在水环境中的迁移转 化行为和归宿 ${ }^{[99]}$. 因此, 有机质吸附, 特别对有毒疏水性有机污染物, 是环境污染控制和生态修复研究中 关键的科学问题，与环境质量基准、技术路线、评价预测和治理等关键技术问题密切相关.

目前主要是有机质对污染物毒性与迁移转化行为的影响程度、机理和程度不清, 某些独特地质条件 下有机质对有机污染物吸附/解吸和生物累积机理和影响机制也尚需要继续开展深人研究; 污染物如何 从土壤或水环境中进入植物或生物, 并在食物链中逐渐富集, 以及形态和毒性的转化机理不清楚. 特别 是有机质对复合污染物行为及其毒性机理的影响研究更少. 未来研究方向运用多学科多手段, 特别是有 机地球化学、生物学和毒理学方面的研究. 内容主要包括: (1)天然有机质与各种污染物之间的相互作用 机理; (2)影响有机质结合或吸附有毒金属或有机污染物能力或强度的主要化学结构、源汇特征及关键控 制要素; (3)地表复杂界面有机质(生物和微生物)对污染物迁移转化、结合和毒性的影响机制; (4)天然有机 质对生物(植物)有毒金属和有机污染物富集机理，包括实内外实验和理论研究; (5)天然有机质作用下有 毒污染物在复合污染条件下的吸附/解吸动力学过程、毒性和生物富集机理.

\section{4 有机质在当前水体富营养化研究中的重要性}

富营养化(Eutrophication)一词最早来源于拉丁语, 其本意是：营养过剩, 水体由于接纳过多的氮、磷 等营养性物质, 导致水生生态系统初级生产力和藻类生物的异常繁殖 ${ }^{[100]}$. 在通常的光照、温度、 $\mathrm{pH}$ 和具 备充分营养物质的条件下，水体中的生物进行光合作用，合成有机质，基本反应式可描述为: $106 \mathrm{CO}_{2}+16 \mathrm{NO}_{3}{ }^{-}+\mathrm{HPO}_{4}{ }^{2-}+122 \mathrm{H}_{2} \mathrm{O}+18 \mathrm{H}^{+}+$能量 + 微量元素 $\rightarrow \mathrm{C}_{106} \mathrm{H}_{263} \mathrm{O}_{110} \mathrm{~N}_{16} \mathrm{P}+138 \mathrm{O}_{2}$. 水体富营养化最直观 的表现为藻类数量的增多和种类的变化, 藻类水华爆发是发生水体富营养化的结果. 藻类异常繁殖的同 时, 水体溶解氧不断下降, 透明度降低, 造成水质恶化, 鱼类大量死亡, 水体毒化等. 水体富营养化是 21 世纪全球环境可持续发展面临的巨大挑战之一 ${ }^{[101]}$, 我国是水体富营养化的重灾区, 特别是长江中下游等 经济发达地区和城市附近的水体. 水体富营养化严重影响着居民的生产和生活, 已成为制约区域社会经 济发展的瓶颈.

水体富营养化可以是由诸多物理因素(温度和光)、化学因素(氮、磷、有机质、䥻、铁、 $\mathrm{pH}$ 、溶解氧 和二氧化碳等)和生物变量共同作用的结果, 氮磷营养盐通常被认为是最重要的因素. 丹麦著名生态学家 Jorgensen指出浮游藻类的生长是富营养化的关键过程 ${ }^{[102]}$. 根据对藻类化学成分的分析研究, Stumm 和 Morgan ${ }^{[51]}$ 提出了藻类的 “经验分子式” 为 $\mathrm{C}_{106} \mathrm{H}_{263} \mathrm{O}_{110} \mathrm{~N}_{16} \mathrm{P}$. 理论上, 水体中每生成 $\lg$ 藻, 需要供给 $0.009 \mathrm{~g}$ 磷和 $0.063 \mathrm{~g}$ 氮. 同时, 利贝格最小值定律指出: 植物生长取决于外界提供给它的所需养料中数量最少的 一种. 由此认为, 磷是湖泊富营养化的主要限制性因素, 当水环境中磷供应量充足时, 藻类便大量迅速 地增殖. 尽管氮也是控制湖泊富营养化的重要元素，但很多藻类(如蓝、绿藻)可通过生物固氮作用从大气 获得充足的氮 ${ }^{[103]}$. 因此, 重点研究氮、磷污染过程、与生物和有机质的耦合, 及其与浮游藻类生产力的 相互作用和关系, 是揭示水体富营养化形成机理的主要途径.

在温带气候地区的湖泊，水温由于受季节变化的影响而引起湖水分层和对流，对水体富营养化也有 着不可忽视的影响. 由于热力分层效应, 使得湖泊水体的表层水在夏季光照充足, 温度较高. 若这时供 
给水体的营养物质充分、藻类光合作用便随之加强, 生长旺盛.同时, 水体的底层往往处于缺氧状态, 很 容易加速底泥磷的释放, 从而导致湖水磷浓度的增加. 秋季湖水的对流使底层的磷迁移到了湖表层, 表 层水中的磷浓度随之提高. 为来年藻类的大量繁殖提供了充足的营养物质, 使得湖泊继续保持富营养状 态. 同时, 富营养化导致水体增加的大量有机碳源，又反过来促使水华藻类的生长，恶性循环. 在中国占 淡水湖泊总数达 $70 \%$ 左右的浅水湖泊富营养化是我国湖泊的突出问题 ${ }^{[104]}$. 相对于深水湖泊, 浅水湖泊更 容易发生富营养化. 由于浅水湖泊一般不会出现分层和季节性变化, 自净能力低, 外源输人很容易向下 输送, 污染路径短. 同时, 污染底泥易受到风浪扰动等水动力条件的影响发生再悬浮, 进而释放营养元 素和有机质到水体中. 外源和内源的共同作用导致了我国浅水湖泊, 尤其是人口分布密集和城市地区的 湖泊, 普遍的富营养化问题 ${ }^{[104-107]}$.

水体中 $\mathrm{pH}$ 、溶解氧和养分循环是水体生态系统良性循环的基础. 大量污染物进人水体后造成水体 $\mathrm{pH}$ 上升, 从而有利于水华藻类的生长, 而藻类大量繁殖又进一步提高水体的 $\mathrm{pH}$, 这样便形成了水质的恶性 循环. 根据光合作用产氧和污染物氧化降解的耗氧过程可知, 水体溶解氧下降有利于蓝藻的生长, 而对 其他藻类生长不利. $\mathrm{CO}_{2}$ 在水中溶解度随水温升高而降低, 当水体氮、磷对藻类生成已达到饱和情况下, 有机碳源也有可能成为限制性因子.

富营养化直接后果是水体颗粒态和溶解态有机质的剧烈增加, 加上氮磷负荷总体水平的增加和水体 物理化学条件的变化, 破坏了健康生态系统中正常的循环规律, 导致有机质和养分循环耦合过程(如: 速 率、通量、主要过程和机制等)发生着明显的变化 ${ }^{[108]}$. 因此, 揭示有机质和养分在水体富营养化生态系统 中的含量、分布和迁移转化等耦合机制将有助于阐述水体富营养化控制与治理, 揭示氮磷污染过程与藻 类水华暴发关系及消除机理，有助于理解富营养化演化规律和趋势.

\section{5 结语}

有机环境与生物地球化学主要是指有机质在生物和生命活动参与下发生的地球化学过程, 包括有机 质(微生物)和营养元素(碳、氮、磷、硅等养分)在地表各圈层和各界面之间的迁移与转化规律, 包括与水 分、养分和各种污染物循环, 及地表物质之间物理、化学与生物的相互作用. 它是集地球化学、生物学、 生态学和环境科学等学科为一体的交叉性研究领域. 有机质与目前主要的生态问题密切相关, 例如: 全 球变化、沙漠化、环境污染与人体健康和水质恶化 ${ }^{[109]}$, 尤其与水体富营养化和环境污染两个重要环境问 题密切相关, 它们也是目前全球范围资源和环境领域内广泛关注的环境问题; 有机环境与生物地球化学 是认识地表生态环境系统的物质和能量循环的基础，可以在为环境污染和水体富营养化的控制与治理、 评价、预测和管理提供重要理论基础. 结合我国特殊区域环境特点, 有机环境与生物地球化学研究可以 为我国经济、社会和科技发展做出重要贡献: 在理论上, 可以为解释区域污染过程与机理，阐述和预测生 态系统演变趋势做贡献; 在决策依据上, 为区域环境质量评价、环境技术与管理及地区可持续发展规划 提供技术支撑, 推动其它学科的发展.

\section{6 参考文献}

[1] Jansson M. Nutrient limitation and bacteria-phytoplankton interactions in humic lakes. In: Hessen DO, Tranvik LJ eds. Aquatic humic substances_ecology and biogeochemistry. Berlin:Springer-Verlag, 1998:178-195.

[2] Moran MA, Zepp RG. Role of photoreactions in the formation of biologically labile compounds from dissolved organic matter. Limnology and Oceanography, 1997, 42(6): 1307-1316.

[3] Wu FC, Tanoue E. Isolation and partial characterization of dissolved copper-complexing ligands in streamwaters. Environmental Science \& Technology, 2001, 35: 3646-3652.

[4] Wu FC, Tanoue E. Molecular mass distribution and fluorescence characteristics of dissolved organic ligands for copper (II) in Lake Biwa, Japan. Organic Geochemistry, 2001, 32:11-20.

[5] Leenheer JA, Croué JP. Characterizating aquatic dissolved organic matter. Environ Sci Technol, 2003, 37: 19-26.

[6] Rice JA. Humin. Soil Science, 2001, 166(11): 848-857. 
[7] Kohl SD, Rice JA. The binding of contaminants to humin: A mass balance. Chemosphere, 1998, 36(2): 251-261.

[8] Donat JR, Bruland KW. Trace elements in the oceans. In: Salbu B, Steinnes E eds. Trace elements in natural waters. Boca Raton, FL:CRC Press, 1995: 247-281.

[9] Yin YJ, Allen HE, Huang CP et al. Kinetics of mercury(II) adsorption and desorption on soil. Environmental Science \& Technology, 1997, 31(2): 496-503.

[10] Gledhill M, Van den berg CMG. Determination of complexation of iron(iii) with natural organic complexing ligands in seawater using cathodic stripping voltammetry. Marine Chemistry, 1994, 47(1): 41-54.

[11] 高全洲, 沈承德, 孙彦敏等. 北江流域有机碳侵蚀通量的初步研究. 环境科学, 2001, 22(2): 12-18.

[12] 李 丽, 张正斌, 刘莲生等. 南黄海胶体有机碳和溶解有机碳的分布.青岛海洋大学学报, 1999, 29(2): 321-324.

[13] 王江涛, 于志刚, 张 经. 鸭绿江口溶解有机碳的研究. 青岛海洋大学学报, 1998, 28(3): 471-475.

[14] 范成新, 王春霞主编. 长江中下游湖泊环境地球化学与富营养化. 北京: 科学出版社, 2007.

[15] 袁华茂, 吕晓霞, 李学刚等. 自然粒度下渤海沉积物中有机碳的地球化学特征. 环境化学, 2003, 22(2): 115-120.

[16] 张甲珅, 陶 澍, 曹 军. 中国东部土壤水溶性有机物苂光特征及地域分异. 地理学报, 2001, 56(4): $409-616$.

[17] 朱广伟, 陈英旭. 沉积物中有机质的环境行为研究进展. 湖泊科学, 2001, 13(3): 272-279.

[18] 苒 勇, 孙 可, 马晓轩等. 土壤和沉积物中的聚合有机质对多环芳烃分布和提取的影响. 生态毒理学报, 2006, 1(4): $336-342$.

[19] 宋长春, 张金波, 张丽华. 氮素输人影响下淡水湿地碳过程变化. 地球科学进展, 2005, 20(11): 1249-1255.

[20] 周东美, 郑春芙，陈怀满. 镉与柠檬酸、EDTA 在几种典型土壤中交互作用的研究. 土壤学报, 2002, 39(1): 29-36.

[21] 洪华生, 王大志. 台湾海峡生源要素生物地球化学过程研究. 厦门大学学报(自然科学版), 2001, 40(2): 535-544.

[22] Vanloon G W, Duffy S J. Environmental Chemistry. New York: Oxford University Press Inc, 2000: 239-257.

[23] Fu PQ, Wu FC, Liu CQ et al. Spectroscopic characterization and molecular weight distribution of dissolved organic matter in sediment porewaters from Lake Erhai, Southwest China. Biogeochemistry, 2006, 81: 179-189.

[24] Wu FC, Evans RD, Dillon PJ. Rapid quantification of humic and fulvic acids bu HPLC in natural waters. Applied Geochemistry, 2007, 22: 1598-1605.

[25] Wu FC, Kothawala DN, Evans RD et al. Relationships between DOC concentration, molecular size and fluorescence properties of DOM in a stream. Applied Geochemistry, 2007, 22: 1659-1667.

[26] Wetzel RG. Limnology, 2nd ed. Philadelphia: Saunders, 1983.

[27] Hwang SJ. Carbon dynamics of plankton communities in nearshore and offshore Lake Erie: The significance of the microbial loop for higher trophic levels[ Ph.D. thesis]. Kent State University, 1995.

[28] 傅平青, 刘丛强, 吴丰昌. 洱海沉积物孔隙水中溶解有机质的三维苂光光谱特征. 第四纪研究, 2004, 24(6): 695-700.

[29] 黎 文, 吴丰昌, 傅平青等. 贵州红枫湖水体溶解有机质的剖面特征和季节变化. 环境科学, 2006, 27(10):1979-1985.

[30] 黎 文, 白英臣, 王立英等. 淡水湖泊水体中溶解有机氮测定方法的对比. 湖泊科学, 2006, 18(1): 63-68.

[31] Sachse A, Henrion R, Gelbrecht J et al. Classification of dissolved organic carbon (DOC) in river systems: Influence of catchment characteristics and autochthonous processes. Org Geochem, 2005, 36: 923-935.

[32] Wu FC, Tanoue E. Tryptophan in the sediments of lakes from Southwestern China Plateau. Chemical Geology, 2002, 184: 139-149.

[33] Wu FC, Tanoue E, Liu CQ. Fluorescence and amino acid characteristics of molecular size fractions of DOM in the waters of Lake Biwa. Biogeochemistry, 2003, 65: 245-257.

[34] Thurman EM. Organic geochemistry of natural waters. Dordrecht: Martinus Nijho./Dr W. Junk Publishers, 1985.

[35] Badr EA, Achterberg EP, Tappin AD. Determination of dissolved organic nitrogen in natural waters using high-temperature catalytic oxidation. Trends in Analytical Chemistry, 2003, 22: 819-827.

[36] Hopkinson C, Cifuentes L. DON subgroup report. Marine Chemistry, 1993, 41: 23-36.

[37] Kitis M, Kilduff JE, Karanfil T. Isolation of dissolved organic matter(DOM) from surface waters using reverse osmosis and its impact on the reactivity of DOM to formation and speciation of disinfection by-products. Water Research, 2001, 35: 2225-2234

[38] Wu FC, Tanoue E. Sensitive determination of dissolved tryptophan in freshwater in alkaline hydrolysis and HPLC. Analytical 
Sciences, 2001, 17: 1063-1066.

[39] McCarthy M, Pratum T, Hedges J et al. Chemical composition of dissolved organic nitrogen in the ocean. Nature, 1997, 390: $150-154$.

[40] Wu FC, Evans RD, Dillon PJ. High-performance chromatographic fractionation and characterization of fulvic acid. Analytica Chimica Acta, 2002, 464: 47-55.

[41] Wu FC, Evans RD, Dillon PJ. Separation and characterization of NOM by high-performance liquid chromatography and on-line three-dimensional excitation emission matrix fluorescence detection. Environmental Science \& Technology, 2003, 37: $3687-3693$.

[42] Fu PQ, Liu CQ, Wu FC. Three-dimensional excitation emission matrix fluorescence spectroscopic characterization of dissolve organic matter. Spectroscopy and Spectral Analysis, 2005, 25(12): 2024-2028.

[43] Wu FC, Cai YR, Evans RD et al. Complexation between $\mathrm{Hg}(\mathrm{II})$ and dissolved organic matter in stream waters: An application of fluorescence spectroscopy. Biogeochemistry, 2004, 71: 339-351.

[44] Xing BS, Pignatello JJ, Gigliotti B. Competitive sorption between atrazine and other organic compounds in soils and model sorbents. Environmental Science \& Technology, 1996, 30(8): 2432-2440.

[45] Wu FC, Evans RD, Dillon PJ. Fractionation and characterization of fulvic acid by immobilized metal ion affinity chromatography. Analytica Chimica Acta, 2002 , 452: 85-92

[46] 岳兰秀, 吴丰昌, 刘丛强等. 红枫湖和百花湖天然溶解有机质的分子苂光特征与分子量分布的关系. 科学通报, 2005, 50(24): 2774-2780.

[47] Wu FC, Liu CQ. 29: Humic substances. In: Leo ML, Nollet eds. Chromatographic analysis of the environment (Third edition). Sound Parkway: CRC Press, 2006: 1155-1173.

[48] Wu FC, Tanoue E. Geochemical characterization of organic ligands for copper (II) in different molecular size fractions in Lake Biwa, Japan. Organic Geochemistry, 2001, 32: 1311-1318.

[49] Alberts JJ, Takacs M, Egeberg PK. Total luminescence spectral characteristics of natural organic matter (NOM) size fractions as defined by ultrafiltration and high performance size exclusion chromatography (HPSEC). Organic Geochemistry, 2002, 33(7): 817-828.

[50] Myneni SCB, Brown JT, Martinez GA et al. Imaging of humic substance macromolecular structures in water and soils. Science, 1999, 286(5443): 1335-1337.

[51] Stumm W, Morgan JJ. Aquatic chemistry: chemical equilibria and rates in natural waters.3rd ed. New York: John Wiley and Sons, 1996: 744

[52] Lee C, Henrichs SM. How the nature of dissolved organic matter might affect the analysis of dissolved organic carbon. Marine Chemistry, 1993, 41: 105-120.

[53] Burdige DJ, Zheng SL. The biogeochemical cycling of dissolved organic nitrogen in estuarine sediments. Limnology and Oceanography, 1998, 43: 1796-1813.

[54] Kappler A, Rong Ji, Schink B et al. Dynamics in composition and size-class distribution of humic substances in profundal sediments of Lake Constance. Organic Geochemistry, 2001, 32: 3-10.

[55] Tarr MA, Wang W, Bianchi TH et al. Mechanisms of ammononia and amino acid photoproduction from aquatic humic and colloidal matter. Water Research, 2001, 35: 3688-3696.

[56] Zuo Y, Jones RD. Photochemistry of natural dissolved organic matter in lake and wetland waters-production of carbon monoxide. Water Research, 1997, 31: 850-858.

[57] Wu FC, Mills B, Cai YR et al. Photodegradation characteristics of dissolved organic matter in acidic waters. Canadian Journal of Fisheries and Aquatic Sciences, 2005, 62: 1019-1027.

[58] Fu PQ, Wu FC, Liu CQ et al. Effect of sunlight irradiation on fluorescence properties of dissolved organic matter. Spectroscopy and Spectral Analysis, 2006, 26 (3): 471-474.

[59] Amon RMW, Benner R. Photochemical and microbial consumption of dissolved organic carbon and dissolved oxygen in the 
Amazon River system. Geochimica et Cosmochimica Acta, 1996, 60: 1783-1792.

[60] Wu FC, Qing HR, Wan GJ et al. Geochemistry of $\mathrm{HCO}_{3}{ }^{-}$in the sediment-water interface of lakes from China Southwestern Plateau. Water Air and Soil Pollution, 1997, 99: 381-390.

[61] Stepanauskas R, Leonardson L, Tranvik LJ. Bioavailability of wetland-derived DON to freshwater and marine bacterioplankton. Limnology and Oceanography, 1999, 44: 1477-1485.

[62] Seitzinger SP, Sanders RW. Atmospheric inputs of dissolved organic nitrogen stimulate estuarine bacteria phytoplankton. Limnology and Oceanography, 1999, 44: 721-730.

[63] Hayakawa K. Seasonal variations and dynamics of dissolved carbohydrates in Lake Biwa. Organic Geochemistry, 2004, 35: 169-179.

[64] Hung CC, Warnken KW, Santschi PH. A seasonal survey of carbohydrates and uronic acids in the Trinity River, Texas. Organic Geochemistry, 2005, 36: 463-474.

[65] Houser JN, Bade DL, Cole JJ et al. The dual influences of dissolved organic carbon on hypolimnetic metabolism: organic substrate and photosynthetic reduction. Biogeochemistry, 2003, 64: 247-269.

[66] Bronk DA. Dynamics of DON. In: Hansell DA, Carlson CA eds. Biogeochemistry of marine dissolved organic matter. San Diego: Academic Press, 2002: 153-249.

[67] Lehmann MF, Bernasconi SM, McKenzie JA. Seasonal variation of the $\delta^{13} \mathrm{C}$ and $\delta^{15} \mathrm{~N}$ of particulate and dissolved carbon and nitrogen in Lake Lugano: Constraints on biogeochemical cycling in a eutrophic lake. Limnology and Oceanography, 2004, 49 (2) : 415-429

[68] Hopkinson CS, Vallino JJ. Efficient export of carbon to the deep ocean through dissolved organic matter. Nature,2005,433: $142-145$.

[69] Bronk DA, Glibert PM, Ward BB. Nitrogen uptake, dissolved organic nitrogen release, and new production. Science, 1994, 265: 1843-1846.

[70] Sharp JH, Rinker KR, Savidge KB et al. A preliminary methods comparison for measurement of dissolved organic nitrogen in seawater. Marine Chemistry, 2002, 78: 171-184.

[71] Carman R, Edlund G, Damberg C. Distribution of organic and inorganic phosphorus compounds in marine and lacustrine sediments: a ${ }^{31}$ P NMR study. Chemical Geology, 2000, 163: 101-114.

[72] Graca B, Bolalek J. Forms of phosphorus in sediments from the Gulf of Gdańsk. Applied Geochemistry, 1998, 13: $319-327$.

[73] Newman RH, Tate KR. Soil phosphorus characterization by ${ }^{31} \mathrm{P}$ nuclear magnetic resonance. Communications in Soil Science and Plant Analysis, 1980, 11: 835-842.

[74] Turner BL, McKelvie ID, Haygarth PM. Characterization of water-extractable soil organic phosphorus by phosphatase hydrolysis. Soil Biology and Biochemistry, 2002, 34: 29-37.

[75] Hupfer M, Gächter R , Rüegger H. Polyphosphate in lake sediments: ${ }^{31}$ P NMR spectroscopy as a tool for its identification. Limnology and Oceanography, 1995, 40(3): 610-617.

[76] Hupfer M, Rübe B, Schmeider P. Origin and diagenesis of polyphosphate in lake sediments: a ${ }^{31} \mathrm{P}$ NMR study. Limnology and Oceanography, 2004, 49(1): 1-10.

[77] Reitzel K, Ahlgren J, Gogoll A et al. Effects of aluminum treatment on phosphorus, carbon, and nitrogen distribution in lake sediment: a ${ }^{31}$ P NMR study. Water Research, 2006, 40: 647-654.

[78] Reitzel K, Ahlgren J, DeBrabandere H et al. Degradation rates of organic phosphorus in lake sediment. Biogeochemistry, 2007, 82(1): $15-28$.

[79] He Z, Senwo ZN , Mankolo RN et al. Phosphorus fractions in poultry litter characterized by sequential fractionation coupled with phosphatase hydrolysis. Journal of Food Agriculture \& Environment, 2006, 4: 304-312.

[80] Tan KH. Humic matter in soil and the environment. New York: Marcel Dekker Inc, 2003.

[81] Mahieu N, Olk DC, Randall EW. Analysis of phosphorus in two humic acid fractions of intensively cropped lowland rice soils by P-31-NMR. European Journal of Soil Science, 2000, 51(3): 391- 402. 
[82] Makarov MI, Malysheva TI. Phosphorus in humus acids. Eurasian Soil Science,2006,39(11): 1208-1216.

[83] Khoshmanesh A, Hart BT, Duncan A. Luxury uptake of phosphorus by sediment bacteria. Water Research, 2002 , 36: $774-778$.

[84] 傅平青, 刘丛强, 吴丰昌. 三维苂光光谱研究溶解有机质与采的相互作用. 环境科学, 2004, 25(6): 140-144.

[85] 傅平青, 刘丛强, 吴丰昌. 水环境中腐殖质-金属离子键合作用研究进展. 生态学杂志, 2004, 23(6): 143-148.

[86] Smith DS, Wu FC. Preface: Metal interactions with natural organic matter. Applied Geochemistry, 2007, $22: 1567$.

[87] 陈静生. 水环境化学. 北京: 高等教育出版社,1987.

[88] 徐晓白, 戴树桂, 黄玉瑶主编. 典型化学污染物在环境中的变化及生态效应. 北京: 科学出版社, 1998.

[89] 陶 澍, 骆永明, 朱利中等. 典型微量有机污染物的区域环境过程. 环境科学学报, 2006, 26(1): 168-171.

[90] 任 曼, 彭平安, 张素坤等. 高分辨气相色谱 / 高分辨质谱联用测定大气降尘中的二噁英. 分析化学, 2006, 34(1): 16-20.

[91] 傅家谟, 盛国英. 环境有机地球化学初探. 地学前缘, 1996, 3(2): 127-132.

[92] Campbell PGC. Interactions between trace metals and aquatic organisms: A critique of the free-ion activity model. In: Tessier A, Turner DR eds. Metal speciation and bioavailability in aquatic systems. John Wiley \& Sons Ltd, 1995: 45-102.

[93] Ohlenbusch G, Kumke MU, Frimmel FH. Sorption of phenols to dissolved organic matter investigated by solid phase microextraction. The Science of the Total Environment, 2000, 253: 63-74.

[94] Morel MM, Price NM. The biogeochemical cycles of trace metals in the oceans. Science, 2003, 300: 944-947.

[95] Wu FC, Midorikawa T, Tanoue E. Fluorescence properties of organic ligands for copper(II) in Lake Biwa and its Rivers. Geochemical Journal, 2001 , 35: 333-346.

[96] Wu FC, Mills B, Evans RD et al. Kinetic of metal-fulvic acid complexation using a stopped-flow technique and three-dimensional excitation emission fluorescence spectrophotometer. Analytical Chemistry, 2004, 76: 110-113.

[97] Wu FC, Mills B, Evans RD et al. Molecular size distribution characteristics of the metal-DOM complexes in stream waters by high-performance size-exclusion chromatography and high-resolution inductively coupled plasma mass spectrometry. Journal of Analytical and Atomic Spectrometry, 2004, 19: 979-983 .

[98] Xing BS, Pignatello JJ. Dual-mode sorption of low polarity compounds in glassy poly(vinyl chloride) and soil organic matter. Environmental Science and Technology, 1997, 31: 792-799.

[99] Bai YC, Wu FC, Liu CQ et al. Interaction between carbamazepine and humic substances: A fluorescence spectroscopic study. Environmental Toxicology and Chemistry (in press), 2008.

[100] Reynolds CS. Phosphorus and the eutrophication of lakes-a personal view. In: Phosphorus in the environment: its chemistry and biochemistry. Ciba Foundation Symposium 57 (new series), 1979: 201-251.

[101] Sharpley A, Tunney H. Phosphorus research strategies to meet agricultural and environmental challenges of the 21 st century. Journal of Environmental Quality, 2000, 29(1): 176-181.

[102] Jorgensen SE. Application of ecology in environmental management. Boca Raton, FL, USA: CRC Press, 1983.

[103] 彭进新，陈慧君. 水质富营养化与防治. 北京：中国环境科学出版社, 1988

[104] 秦伯强，杨柳燕，陈非洲等. 湖泊富营养化发生机制与控制技术及其应用. 科学通报, 2006, 51(16): 1857-1866.

[105] 朱广伟, 秦伯强, 高 光. 风浪扰动引起大型浅水湖泊内源磷暴发性释放的直接证据. 科学通报, 2005, 50(1): 66-71.

[106] 范成新, 张 路, 秦伯强等. 风浪作用下太湖悬浮态颗粒物中磷的动态释放估算. 中国科学(D辑), 2003, 33(8): 760-768.

[107] 张运林, 秦伯强. 太湖水体富营养化的演变及研究进展. 上海环境科学, 2001, 20(6): 263-265.

[108] 吴敬禄, 王苏民. 云南程海富营养化过程的碳氧稳定同位素示踪. 第四纪研究, 2003, 23(5): 557-564.

[109] Zsolnay A. Dissolved organic matter: artifacts, definitions, and functions. Geoderma, 2003, 113: 187- 209. 